Article

\title{
Efficient Dehydration of Fructose to 5-Hydroxy- methylfurfural Catalyzed by Heteropolyacid Salts
}

\author{
Yanlei Song ${ }^{1}$, Xincheng Wang ${ }^{1}$, Yongshui Qu ${ }^{2}$, Chongpin Huang ${ }^{1, *}$, Yingxia Li $^{1}$ \\ and Biaohua Chen ${ }^{1}$ \\ 1 State Key Laboratory of Chemical Resource Engineering, Beijing University of Chemical Technology, \\ Beijing 100029, China; syllwy@126.com (Y.S.); wxcnathan@gmail.com (X.W.); liyx@mail.buct.edu.cn (Y.L.); \\ chenbh@mail.buct.edu.cn (B.C.) \\ 2 National Key Laboratory of Biochemical Engineering, Institute of process Engineering, \\ Chinese Academy of Sciences, Beijing 100190, China; quyongshui@126.com \\ * Correspondence: huangcp@mail.buct.edu.cn; Tel.: +86-10-6441-2054 \\ Academic Editor: Rafael Luque \\ Received: 14 November 2015; Accepted: 16 February 2016; Published: 23 March 2016
}

\begin{abstract}
Hydroxymethylfurfural (5-HMF), which is derived from numerous industrial biomass resources, has attracted attention in recent years due to its potential as a building block. In this paper, a range of heteropolyacid salts had been investigated for the dehydration of fructose to 5-HMF. $\mathrm{CePW}_{12} \mathrm{O}_{40}$ demonstrated the best catalytic activity. Effects of fructose concentration, reaction temperature and reaction time on 5-HMF yield were investigated and optimised through a central composite design and response surface methodology. The optimal 5-HMF yield was $99.40 \%$ under the optimized reaction conditions of $5.48 \mathrm{mg} / \mathrm{mL}$ fructose loading, $158{ }^{\circ} \mathrm{C}$ temperature and $164 \mathrm{~min}$ reaction time. A kinetic analysis of the fructose conversion was also performed, and the activation energy and pre-exponential factor were obtained.
\end{abstract}

Keywords: 5-hydroxymethylfurfural; dehydration; fructose; heteropolyacid salt; response-surfacemethodology optimisation

\section{Introduction}

The massive consumption of unsustainable fossil resources has stimulated the search for renewable resources [1,2]. Biomass has the potential to serve as sustainable resources for the production of fuel and chemicals [3,4]. 5-Hydroxymethylfurfural (5-HMF) is one of the top biomass-derived building blocks from which a wide range of value-added compounds can be synthesised, such as 5-dimethylfuran, 2,5-furandicarboxylic acid, levulinic acid, and so on [5-9]. The dehydration of fructose to 5-HMF has attracted considerable attention in the past few years [10]. Water, organic solvents, organic/water mixtures and a few other biphasic systems have been used as reaction solvents during this process [11-13].

Preparation of 5-HMF by chemical catalysis involves mainly dehydration of sugars, which can be efficiently catalyzed by acid catalysts [14]. Mineral acids $\left(\mathrm{H}_{2} \mathrm{SO}_{4}, \mathrm{HCl}\right.$ and $\left.\mathrm{HNO}_{3}\right)$ and transition metal salts have been widely used in the production of 5-HMF [15-19]. However, the homogeneous methods suffers from complicated separation processes especially considering the regeneration of the system. Therefore, heterogeneous catalysts have been proposed. It's worthwhile to mention that the heterogeneous acid catalysts have shown superior activity to homogeneous catalysts in terms of 5-HMF selectivity [20]. H-form zeolites and metal phosphates showed 5-HMF selectivities of $60 \%-90 \%$ with fructose conversions in the 30\%-60\% range [21,22]. Dumesic et al. reported that acidic ion-exchange resin could effectively catalyze the dehydration of $30 \mathrm{wt}$ \% fructose to 5-HMF, resulting into $60 \%$ selectivity with $89 \%$ fructose conversion [13]. Sulfated zirconia was also demonstrated 
to be active for the production of 5-HMF with yield as high as 72.8\% [23]. Heteropolyacid salts are well-known solid acid catalysts that have been utilised in various important commercial reactions, such as esterifications, isomerisations and etherifications. Shimizu evaluated the activity of heteropolyacid by simple water removal methods and found that Amerlyst-15 and FePW ${ }_{12} \mathrm{O}_{40}$ could catalyze the conversion of high concentration fructose (50 wt. \%) to 5-HMF with yields reached approximately $100 \%$ and $50 \%$, respectively [24]. In addition, $\mathrm{H}_{3} \mathrm{PW}_{12} \mathrm{O}_{40}$ and the corresponding cesium salts were used for dehydration of $50 \mathrm{wt} \%$ fructose in a DMSO-polyvinylpyrrolidone system with 52\% and 58\% 5-HMF yields [25]. Wang et al. demonstrated that $\mathrm{Cs}_{2.5} \mathrm{H}_{0.5} \mathrm{PW}_{12} \mathrm{O}_{40}$ exhibited 5-HMF selectivity of $94.7 \%$ with a final yield of $74 \%$ in a biphsic system of water-methylisobutylketone [26].

In the present study, several types of heteropolyacid salts were synthesised and utilised for the catalytic dehydration of fructose to 5-HMF with optimum yields over 99\%. sec-Butanol was demonstrated to be the best reaction solvent. A central composite design (CCD) and response surface methodology (RSM) were employed to design experiments and optimise the conversion. Finally, several kinetic parameters for the reaction were obtained.

\section{Results and Discussion}

\subsection{Effect of Reaction Medium on the Fructose to 5-HMF Conversion Yield}

The comparative XRD and IR spectra of the heteropolyacid salts are presented in Figures 1 and 2. In the wavenumber region from 700 to $1100 \mathrm{~cm}^{-1}$, the fingerprint vibrational bands of Keggin anions are observed. The XRD measurement indicated that the crystalline structures of the HPAs still remained in the metal-substituted form. Different heteropolyacid salts and solvents were employed for the dehydration of fructose. The blank references of DMSO, n-butanol and sec-butanol showed that DMSO was the most effective solvent without catalyst. Different catalysts significantly affected the conversion of fructose into 5-HMF (Table 1, entries 5-9). Among the catalysts tested, $\mathrm{CePW}_{12} \mathrm{O}_{40}$ and $\mathrm{Zn}_{1.5} \mathrm{PW}_{12} \mathrm{O}_{40}$ showed the strongest and weakest catalytic activities, affording $88.78 \%$ and $26.22 \%$ 5-HMF, respectively (Table 1, entries 5 and 9). In addition, the yield of 5-HMF increased as the reaction time was prolonged with only slightly higher conversion of fructose (Table 1, entries 9 and 11).

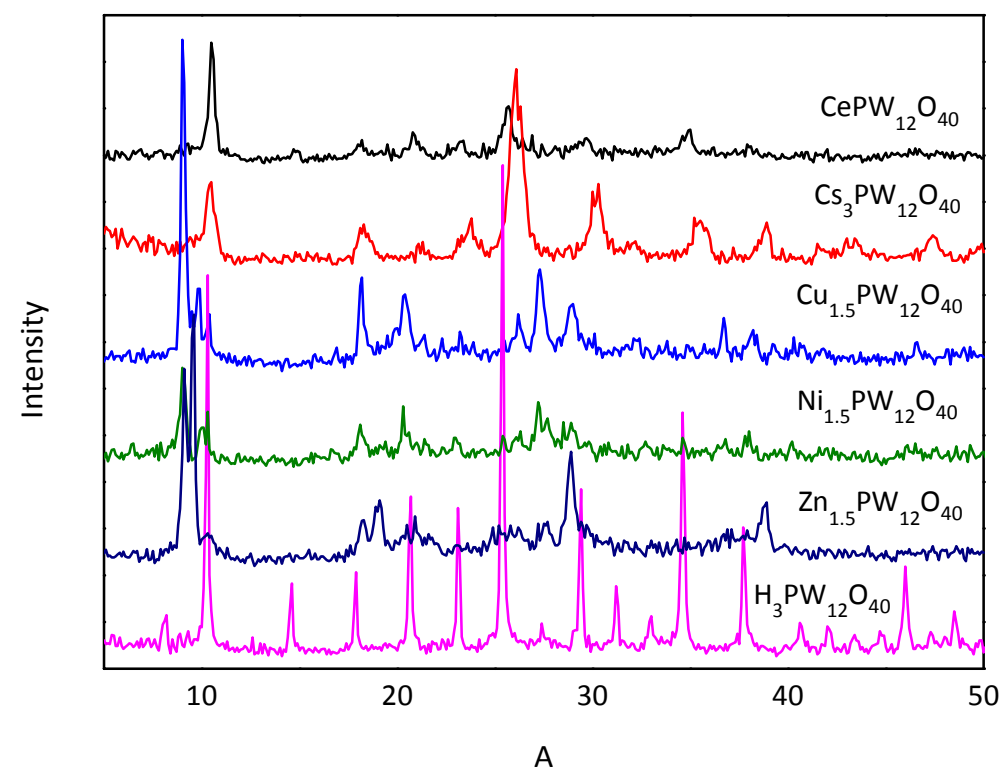

Figure 1. XRD patterns of heteropolyacid salts. 


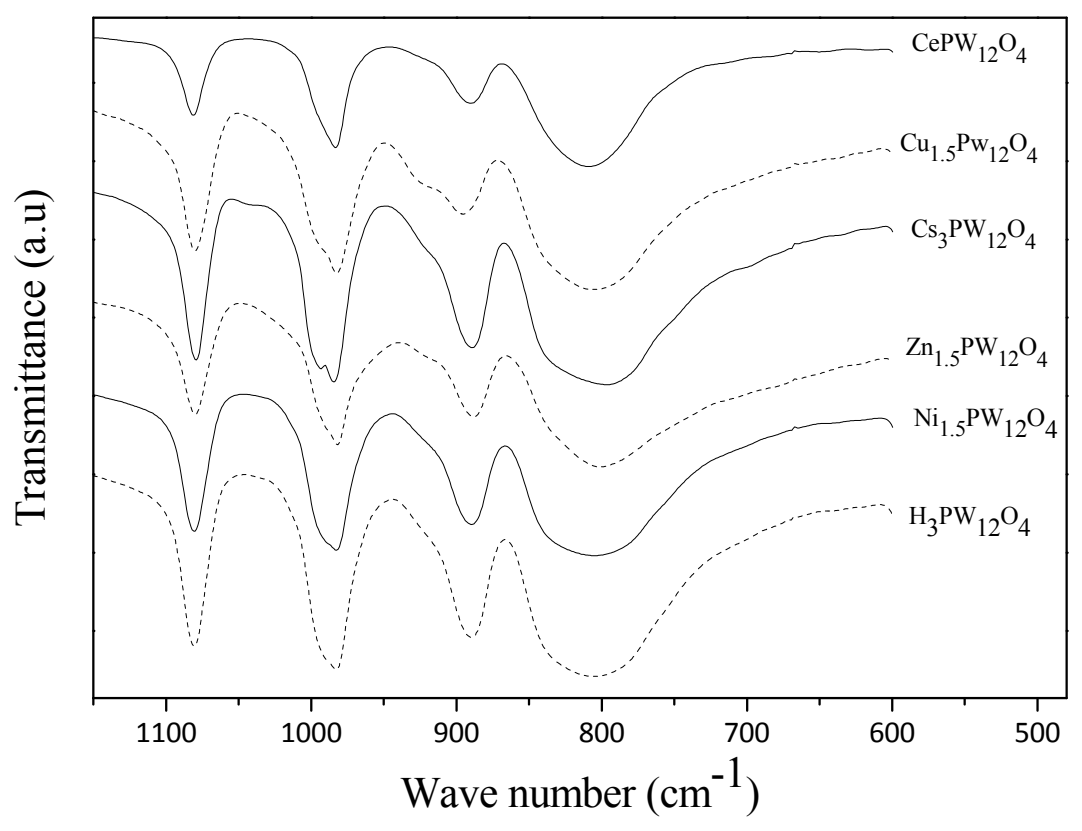

Figure 2. FTIR spectra of heteropolyacid salts.

Table 1. Conversion of fructose to 5-HMF with different solvents and catalysts.

\begin{tabular}{cccccc}
\hline Entry & Solvent & Catalyst & Reaction Time/min & Conv. \% & Yield \% \\
\hline 1 & DMSO & Blank & 60 & 18.11 & 17.53 \\
2 & $n$-Butanol & Blank & 60 & 1.56 & 0.58 \\
3 & $s e c-$ Butanol & Blank & 60 & 2.15 & 1.04 \\
4 & $s e c-$ Butanol & $\mathrm{K}_{3} \mathrm{PW}_{12} \mathrm{O}_{40}$ & 60 & 75.85 & 71.43 \\
5 & DMSO & $\mathrm{Zn}_{1.5} \mathrm{PW}_{12} \mathrm{O}_{40}$ & 60 & 27.52 & 26.22 \\
6 & DMSO & $\mathrm{Ni}_{1.5} \mathrm{PW}_{12} \mathrm{O}_{40}$ & 60 & 62.42 & 60.67 \\
7 & DMSO & $\mathrm{Cs}_{3} \mathrm{PW}_{12} \mathrm{O}_{40}$ & 60 & 75.73 & 73.59 \\
8 & DMSO & $\mathrm{Cu}_{1.5} \mathrm{PW}_{12} \mathrm{O}_{40}$ & 60 & 85.68 & 82.71 \\
9 & DMSO & $\mathrm{CePW}_{12} \mathrm{O}_{40}$ & 60 & 89.61 & 88.78 \\
10 & DMSO & $\mathrm{Cu}_{1.5} \mathrm{PW}_{12} \mathrm{O}_{40}$ & 120 & 93.79 & 86.22 \\
11 & DMSO & $\mathrm{CePW}_{12} \mathrm{O}_{40}$ & 120 & 96.23 & 93.86 \\
12 & DMAc & $\mathrm{CePW}_{12} \mathrm{O}_{40}$ & 120 & 91.35 & 90.13 \\
13 & MIBK & $\mathrm{CePW}_{12} \mathrm{O}_{40}$ & 120 & 88.92 & 86.74 \\
14 & $n$-Butanol & $\mathrm{CePW}_{12} \mathrm{O}_{40}$ & 120 & 98.56 & 97.48 \\
15 & $s e c-$ Butanol & $\mathrm{CePW}_{12} \mathrm{O}_{40}$ & 120 & 99.10 & 98.15 \\
\hline
\end{tabular}

Different protic (butanols) and aprotic (MIBK, DMSO, etc.) solvents were employed in the dehydration of fructose with $\mathrm{CePW}_{12} \mathrm{O}_{40}$ as the catalyst (Table 1, entries 11-15). Protic solvents performed better than the aprotic ones and sec-butanol was determined to be the most efficient solvent (Table 1, entry 15), showing that $\mathrm{CePW}_{12} \mathrm{O}_{40}$ exhibited the highest catalytic activity in the fructose conversion among the protic solvents. Moreover, the $\mathrm{CePW}_{12} \mathrm{O}_{40}$-sec-butanol combination behaved as a thermoregulated system and there was a phase change from heterogeneous towards homogeneous catalysis during the reaction (Figure 3). After cooling down, the reaction solution turned heterogeneous again and the catalysts could be removed from the reaction mixture by simple filtration. 


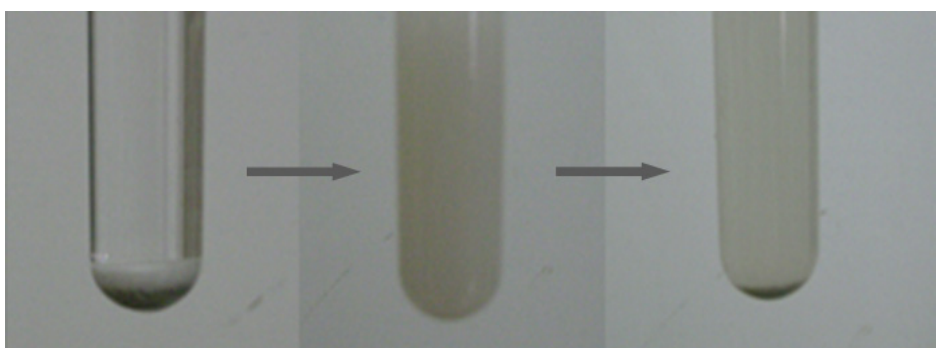

Figure 3. The conversion of fructose to 5-HMF over $\mathrm{CePW}_{12} \mathrm{O}_{40}$ in sec-butanol.

\subsection{Optimization of Process Conditions}

The conversion of fructose into 5-HMF catalyzed by $\mathrm{CePW}_{12} \mathrm{O}_{40}$ in sec-butanol was optimised by CCD in the RSM. The correlation among fructose loading $\left(X_{1}\right)$, temperature $\left(X_{2}\right)$ and reaction time $\left(X_{3}\right)$ was estimated by ANOVA. The 5-HMF yield was used as the response to evaluate the conversion efficiency and the targets of optimisation.

The results of ANOVA with the 5-HMF yield as the response are shown in Table 2. The Model $F$-value of 1275.81 implies that the model is significant. The "Model F-Value" could obtain this value with only a $0.01 \%$ chance because of noise. Values of "Prob $>F^{\prime}$ " less than 0.05 indicate that the model terms are significant. In this case, $\mathrm{B}, \mathrm{C}, \mathrm{AB}, \mathrm{AC}, \mathrm{BC}, \mathrm{A}^{2}, \mathrm{~B}^{2}$ and $\mathrm{C}^{2}$ were the significant model terms. The "Lack of Fit F-value" of 4.55 and " $p$-value" of $0.0862(>0.05)$ imply that the Lack of Fit is not significant. "Adeq Precision" measures the signal-to-noise ratio. A ratio greater than 4 is desirable. The ratio of 107.66 indicates an adequate signal. The results showed that this model was statistically sound and can be utilised to navigate the design space. The final equation in terms of the coded factors can be expressed as:

$$
\begin{aligned}
y=98.22-0.68 x_{1}- & -6.66 x_{2}+12.78 x_{3}-13.65 x_{1}^{2}-21.51 x_{2}^{2}-12.94 x_{3}^{2}-6.21 x_{1} x_{2} \\
& -8.96 x_{1} x_{3}-9.94 x_{2} x_{3}+3.19 x_{1}^{2} x_{2}+2.66 x_{1}^{2} x_{3}+2.38 x_{1} x_{2}^{2}+3.99 x_{1}^{2} x_{2}^{2}
\end{aligned}
$$

The similarity between the predicted and actual values is described in Figure 4 . The coefficient of determination $\left(R^{2}\right)$ value was 0.9001 , indicating a close agreement between the experimental and theoretical values.

\begin{tabular}{|c|c|c|c|c|c|c|}
\hline \multirow{2}{*}{$\frac{\text { Source }}{\text { Model }}$} & \multirow{2}{*}{$\frac{\text { Sum of Squares }}{14047.75}$} & \multirow{2}{*}{$\frac{\mathbf{D F}^{*}}{13}$} & \multirow{2}{*}{$\frac{\text { Mean Square }}{1080.60}$} & \multirow{2}{*}{$\begin{array}{c}\boldsymbol{F} \text {-Value } \\
1275.81\end{array}$} & \multicolumn{2}{|c|}{ Probability $>F$} \\
\hline & & & & & $<0.0001$ & Significant \\
\hline A & 2.62205 & 1 & 2.62 & 3.10 & 0.1290 & - \\
\hline $\mathrm{B}$ & 250.6561 & 1 & 250.66 & 295.94 & $<0.0001$ & - \\
\hline $\mathrm{C}$ & 923.6402 & 1 & 923.64 & 1090.50 & $<0.0001$ & - \\
\hline $\mathrm{AB}$ & 308.7613 & 1 & 308.76 & 364.54 & $<0.0001$ & - \\
\hline $\mathrm{AC}$ & 641.8945 & 1 & 641.89 & 757.85 & $<0.0001$ & - \\
\hline $\mathrm{BC}$ & 790.8265 & 1 & 790.83 & 933.69 & $<0.0001$ & - \\
\hline $\mathrm{A}^{2}$ & 2237.45 & 1 & 2237.45 & 2641.65 & $<0.0001$ & - \\
\hline $\mathrm{B}^{2}$ & 5554.388 & 1 & 5554.39 & 6557.81 & $<0.0001$ & - \\
\hline$C^{2}$ & 2010.072 & 1 & 2010.07 & 2373.20 & $<0.0001$ & - \\
\hline$A^{2} B$ & 33.64851 & 1 & 33.65 & 39.73 & 0.0007 & - \\
\hline$A^{2} C$ & 23.48121 & 1 & 23.48 & 27.72 & 0.0019 & - \\
\hline $\mathrm{AB}^{2}$ & 18.70431 & 1 & 18.70 & 22.08 & 0.0033 & \\
\hline $\mathrm{A}^{2} \mathrm{~B}^{2}$ & 50.90518 & 1 & 50.91 & 60.10 & 0.0002 & - \\
\hline Residual & 5.081933 & 6 & 0.85 & - & - & - \\
\hline Lack of Fit & 2.42 & 1 & 2.42 & 4.55 & 0.0862 & Not significant \\
\hline Pure Error & 2.661933 & 5 & 0.53 & - & - & - \\
\hline Cor Total & 14052.83 & 19 & - & - & - & - \\
\hline
\end{tabular}

Table 2. ANOVA table for the quadratic model. 


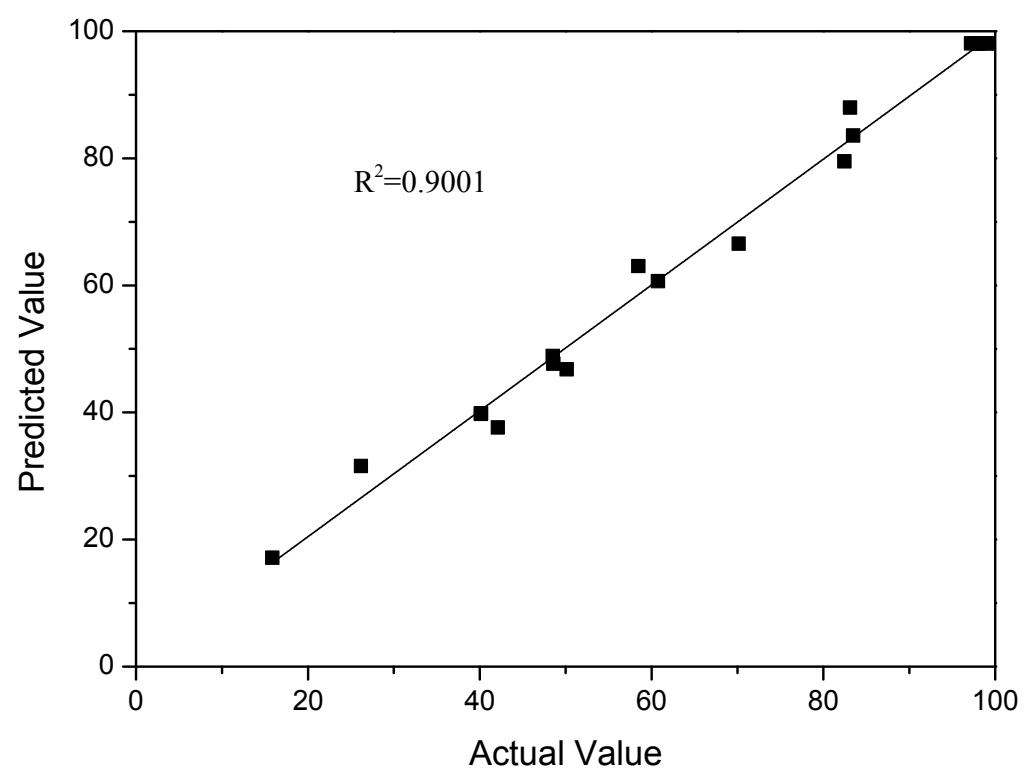

Figure 4. Predicted vs. actual 5-HMF yield.

The 3-D response surface and the 2-D contour plots that show the effects of the variables on the 5-HMF yield are displayed in Figure 5. The interactive effects of independent variables on the responses were obtained by remaining one variable constant and changing the other two variables. The interaction between factors A and B on the 5-HMF yield is shown in Figure 5A. As the fructose loading and temperature increased, the 5-HMF yield rapidly increased, peaked and then decreased when the reaction time was prolonged. This result indicated that the degradation of 5-HMF was significant. Tarry materials were also formed; these materials were likely generated by the polymerisation and cross-polymerisation of 5-HMF and intermediates that readily occur at high temperatures and fructose amount. This finding could account for the decreased yield of 5-HMF. Figs. 5B and 5C also show the presence of two-way interactions between variables, namely, fructose loading and temperature, fructose loading and reaction time as well as temperature and reaction time. Moreover, the sequence of the three factors that affected the 5-HMF yield from strong to weak was $\mathrm{C}>\mathrm{B}>\mathrm{A}$. This finding is consistent with the results listed in Table 2.
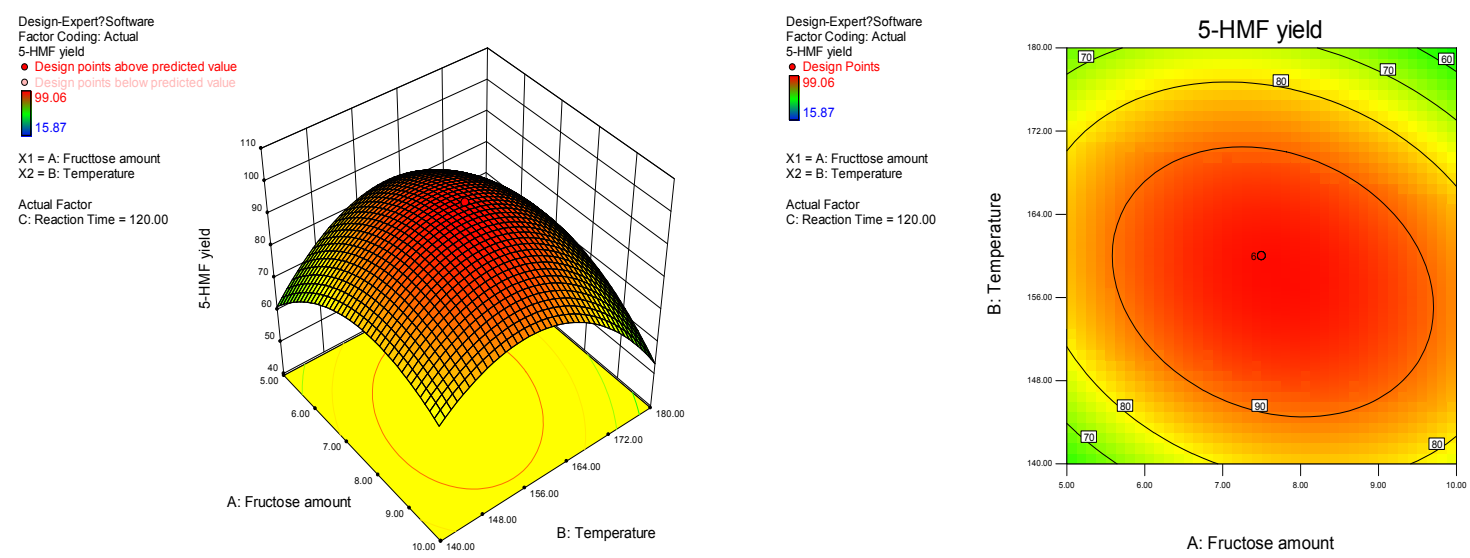

(A)

Figure 5. Cont. 

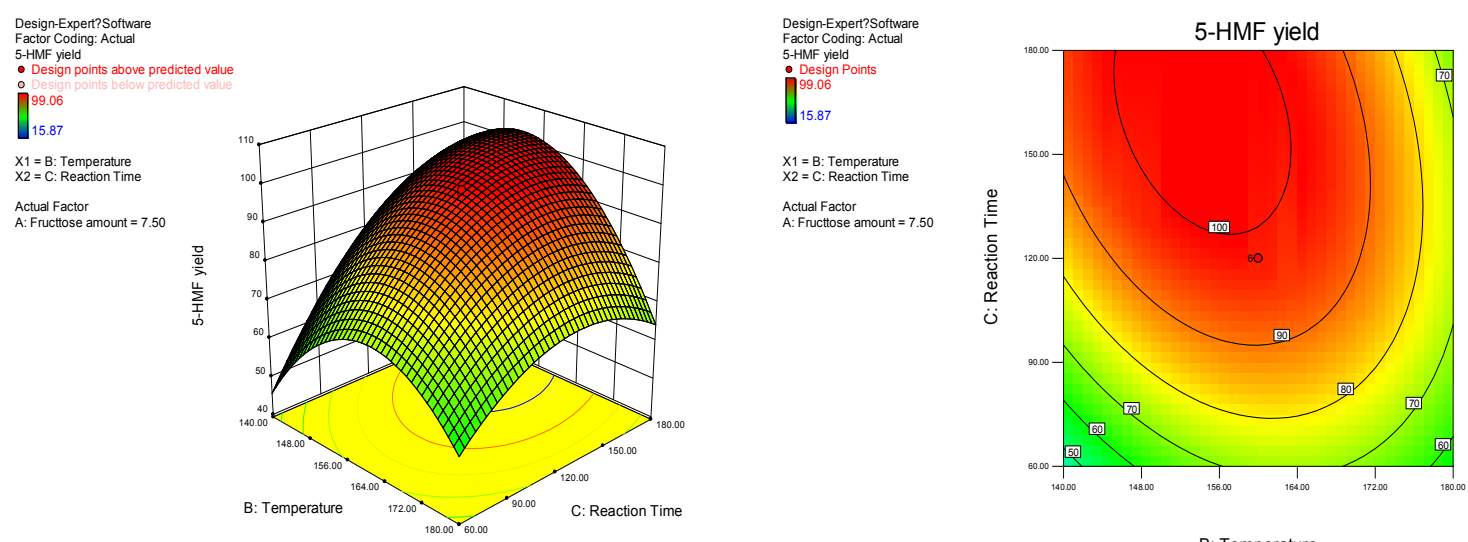

B: Temperature

(B)
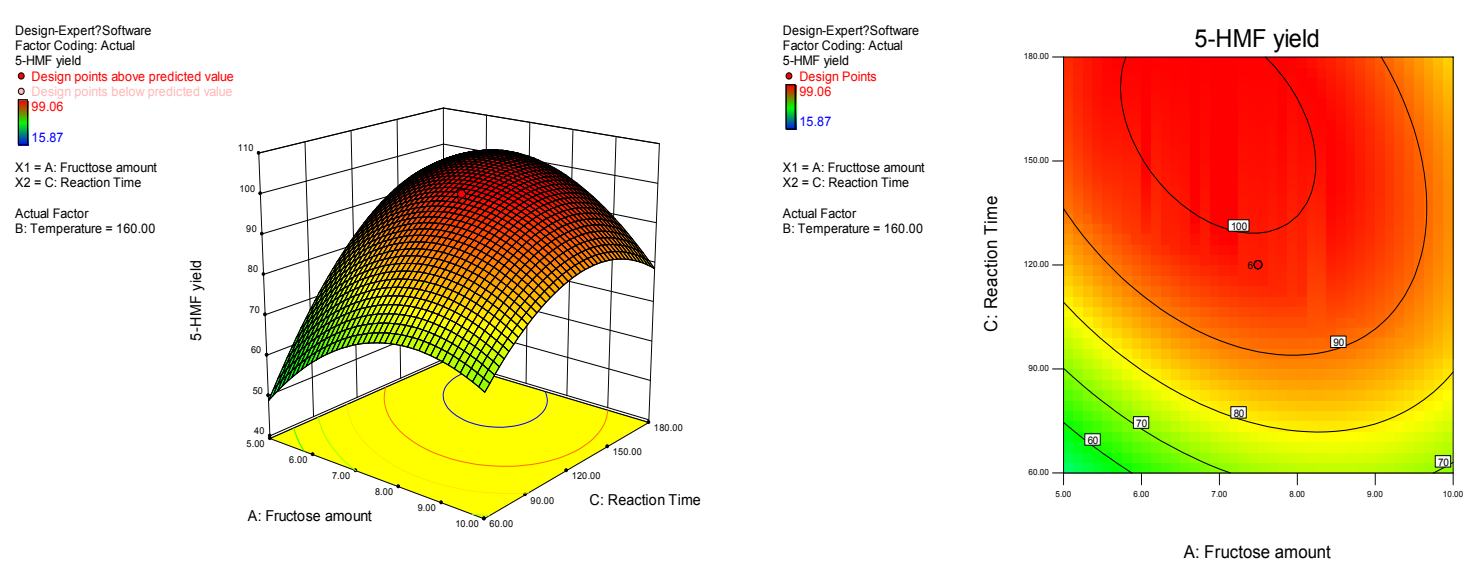

(C)

Figure 5. Response fitted surface area and contour plot for 5-HMF yield based on (A) temperature and fructose loading; (B) reaction time and temperature and $(\mathbf{C})$ fructose loading and reaction time.

\subsection{Optimisation and Confirmation Experiments}

The optimal 5-HMF yield was $99.40 \%$ under the following reaction conditions: $5.48 \mathrm{mg} / \mathrm{mL}$ fructose loading; $158{ }^{\circ} \mathrm{C}$ temperature; and $164 \mathrm{~min}$ reaction time. Under the same conditions, the actual value $(99.60 \%$ ) obtained from the experiments was within the $95 \%$ prediction interval, implying that the prediction models were reasonable and credible.

\subsection{Catalyst Recycling}

After the reaction, the mixture was distilled and collected to pure sec-butanol. The remaining mixture was extracted with ethyl acetate after the addition of $0.5 \mathrm{~mL}$ water according to the procedure reported previously. $\mathrm{CePW}_{12} \mathrm{O}_{40}$ and sec-butanol were recycled at least six cycles without significant loss of activity and the yield of 5-HMF was still 93.3\% after six runs (Figure 6). The slight decrease in 5 -HMF yield could be ascribed to the intensive formation of humins during the reaction; this could be observed from the viscous solutions produced after long reaction times. 


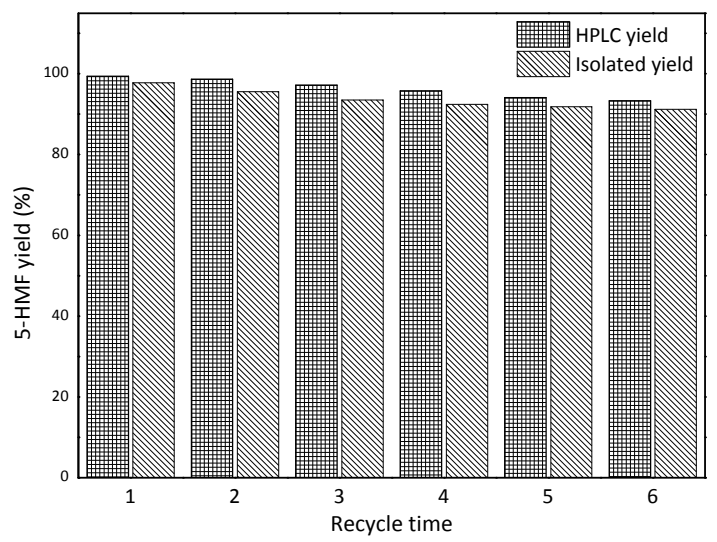

Figure 6. Recycle of $\mathrm{CePW}_{12} \mathrm{O}_{40}$ and sec-butanol $\left(5.48 \mathrm{mg} / \mathrm{mL}\right.$ of fructose, $1.0 \mathrm{~g}$ of catalyst, $158{ }^{\circ} \mathrm{C}$, $164 \mathrm{~min})$.

\subsection{Kinetic Model}

Various kinetic analysis of acid-catalysed hydrolysis of carbohydrates have been reported in the literature $[27,28]$. In the present study, a kinetic analysis of the fructose dehydration catalyzed by $\mathrm{CePW}_{12} \mathrm{O}_{40}$ was performed in DMSO so as to make direct comparison with other catalysts used in the same reaction solvent. The kinetic curves shown in Figure 7 correspond to temperatures from 80 to $160{ }^{\circ} \mathrm{C}$. The values of $\ln (1-X)$ (where $X$ is the conversion of fructose) were plotted against the reaction time $(t)$ to obtain the pseudo-first-order rate constant $(k)$. This model has been employed in most of the kinetic studies because it provides reasonable levels of agreement with experimental data [29]. Table 3 shows that the value of $k$ increased when increasing the reaction temperature, indicating that a higher reaction temperature is beneficial for the dehydration process.

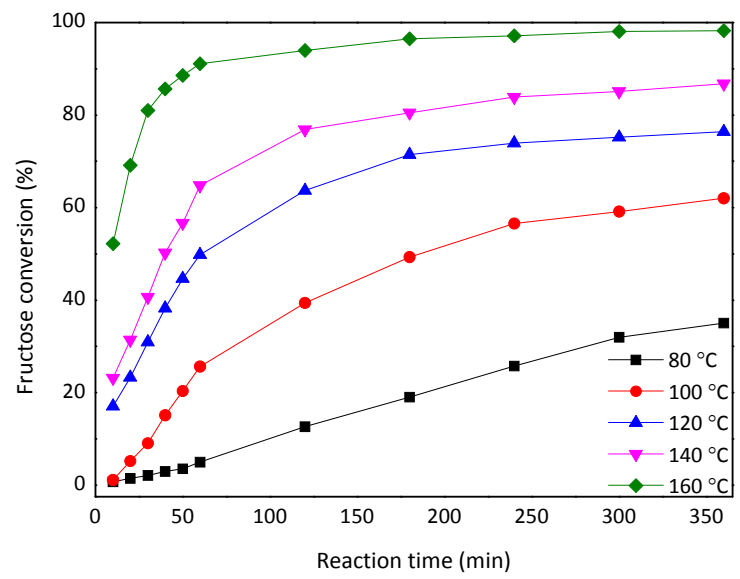

Figure 7. Fructose conversion when increasing the temperature from 80 to $160{ }^{\circ} \mathrm{C}$.

Table 3. Rate constants $(k)$ of fructose conversion at different reaction temperatures with $\mathrm{CePW}_{12} \mathrm{O}_{40}$ as the catalyst.

\begin{tabular}{cccc}
\hline Entry & Temperature $\left({ }^{\circ} \mathbf{C}\right)$ & $\boldsymbol{k}\left(\mathbf{m i n}^{-1}\right)$ & Correlation Coefficient \\
\hline 1 & 80 & $0.001131 \pm 9.1531 \times 10^{-5}$ & 0.9963 \\
2 & 100 & $0.001761 \pm 4.0587 \times 10^{-5}$ & 0.9934 \\
3 & 120 & $0.002755 \pm 3.3841 \times 10^{-4}$ & 0.9959 \\
4 & 140 & $0.004421 \pm 2.4758 \times 10^{-4}$ & 0.9872 \\
5 & 160 & $0.006069 \pm 1.1199 \times 10^{-4}$ & 0.9973 \\
\hline
\end{tabular}


An Arrhenius plot was generated by using the values of $k$. The activation energy and pre-exponential factor for the $\mathrm{CePW}_{12} \mathrm{O}_{40}$-catalysed dehydration of fructose to 5-HMF are listed in Table 4. The activation energy was $27.21 \mathrm{~kJ} / \mathrm{mol}$, which is much lower than the value $(55.77 \mathrm{~kJ} / \mathrm{mo})$ obtained while using 1-hydroxyethyl-3-methylimidazolium tetrafluoroborate $\left[\left(\mathrm{C}_{2} \mathrm{OHMIM}\right) \mathrm{BF}_{4}\right]$ as the catalyst and DMSO as the solvent [30]. This result indicated that the system involving $\mathrm{CePW}_{12} \mathrm{O}_{40}$ efficiently reduced the activation energy and increased the reaction rate, indicating the high catalytic activity of $\mathrm{CePW}_{12} \mathrm{O}_{40}$.

Table 4. Kinetic parameters of the degradation of fructose with the $\mathrm{CePW}_{12} \mathrm{O}_{40}$ catalyst.

\begin{tabular}{cc}
\hline Kinetic Parameters & Value \\
\hline Reaction order, $n$ & 1.0 \\
Activation energy, $E a(\mathrm{~kJ} / \mathrm{mol})$ & 27.21 \\
Pre-exponential factor, $A(\mathrm{~min}-1)$ & 11.72 \\
Correlation coefficient & 0.9869 \\
\hline
\end{tabular}

\section{Experimental Section}

\subsection{Materials and Catalyst Preparation}

5-HMF, cesium carbonate $\left(\mathrm{Cs}_{2} \mathrm{CO}_{3}\right)$ and cerous carbonate $\left(\mathrm{Ce}_{2}\left(\mathrm{CO}_{3}\right)_{3}\right)$ were purchased from Shanghai Jingchun Chemical Reagent Company (Shanghai, China); sec-butanol, dimethyl sulfoxide (DMSO), dimethylacetamide (DMAc), N-methylpyrrolidone, fructose, zinc nitrate $\left[\mathrm{Zn}\left(\mathrm{NO}_{3}\right)_{2}\right]$, cupric nitrate $\left[\mathrm{Cu}\left(\mathrm{NO}_{3}\right)_{2}\right]$ and nickel nitrate $\left[\mathrm{Ni}\left(\mathrm{NO}_{3}\right)_{2}\right]$ were purchased from Beijing Chemical Reagent Company (Beijing, China). All reagents were utilised as received without further purification.

The heteropolyacid salts were synthesised through the following method: phosphotungstic acid $(30.0 \mathrm{~g}, 9.6 \mathrm{mmol})$ was dissolved in deionised water $(100 \mathrm{~mL})$ followed by the dropwise addition of cesium carbonate $(4.7 \mathrm{~g}, 14.5 \mathrm{mmol})$. The obtained solution was then stirred for another $2 \mathrm{~h}$ at $40{ }^{\circ} \mathrm{C}$ under nitrogen atmosphere. $\mathrm{Cs}_{3} \mathrm{PW}_{12} \mathrm{O}_{40}$ was obtained after evaporating under vacuum at $60{ }^{\circ} \mathrm{C}$ for $6 \mathrm{~h}$. The yield of $\mathrm{Cs}_{3} \mathrm{PW}_{12} \mathrm{O}_{40}$ was $90.1 \%$. Other heteropolyacid salts were prepared using similar procedures.

\subsection{General Procedure for the Conversion of Fructose to 5-HMF}

In a typical reaction, $1.0 \mathrm{~g}$ of fructose, $0.1 \mathrm{~g}$ of catalyst and $60 \mathrm{~mL}$ of solvent were placed in a $100 \mathrm{~mL}$ flask fitted with a condenser under a nitrogen atmosphere and heated to the appropriate temperature for the selected amount of time. After the reaction, the mixture was analysed by high-performance liquid chromatography (ProStar 310 with a UV detector, Varian, Palo Alto, CA, USA) equipped with a C18 column using methanol/water $(40 / 60, v / v)$ as the eluent at a flow rate of $1.0 \mathrm{~mL} / \mathrm{min}$. The yield of 5-HMF (\%) was evaluated on a carbon basis as:

$$
Y=\frac{\text { Moles of } 5-\text { HMF }}{\text { Staeting amount of fructose }} \times 100 \%
$$

\subsection{Design of Experiments}

The effect of three independent variables (temperature, reaction time and fructose loading) on the response (5-HMF yield) was studied by employing a factorial CCD of RSM, which was a collection of mathematical and statistical techniques for designing experiments, analysing the effects of variables, developing models and optimising the process variables to obtain the optimum response [31-34]. The experimental data were fitted with a low-order polynomial equation to evaluate the effect of each independent variable to the response, which was later analysed to determine the optimum process conditions. In this study, the following polynomial quadratic equation was employed: 


$$
y=\beta_{0}+\sum_{i=1}^{3} \beta_{i} x_{i}+\sum_{i=1}^{3} \beta_{i i} x_{i}^{2}+\sum_{i=1}^{3} \sum_{j=i+1}^{3} \beta_{i j} x_{i} x_{j}
$$

where $y$ is the response function, $x_{i}$ and $x_{j}$ are the independent variables, $\beta_{0}$ is the constant coefficient, $\beta_{i}$ is the linear coefficient, $\beta_{i i}$ is the quadratic coefficient and $\beta_{i j}$ is the interaction coefficient among the variables. For fitting second-order models, $C C D$ is one of the most commonly utilised response surface designs.

Each variable was investigated at three coded levels $(-1,0,1)$, as listed in Table 5 . The complete experimental design matrix and 5-HMF yields are shown in Table 6. The data obtained from the CCD were analysed by employing Design-Expert software version 8.0.6 (Stat-Ease Inc., Minneapolis, $\mathrm{MN}, \mathrm{USA}$ ).

Table 5. Range and levels of independent variables.

\begin{tabular}{cccccc}
\hline \multirow{2}{*}{ Variable } & \multirow{2}{*}{ Unit } & \multirow{2}{*}{ Symbol } & \multicolumn{3}{c}{ Range and Level } \\
\cline { 4 - 6 } & & & $\mathbf{- 1}$ & $\mathbf{0}$ & $\mathbf{1}$ \\
\hline Fructose loading & $\mathrm{mg} / \mathrm{mL}$ & $x_{1}$ & 5.0 & 7.5 & 10 \\
Temperature & ${ }^{\circ} \mathrm{C}$ & $x_{2}$ & 140 & 160 & 180 \\
Reaction time & $\mathrm{min}$ & $x_{3}$ & 60 & 120 & 180 \\
\hline
\end{tabular}

Table 6. Experimental design matrix and results.

\begin{tabular}{cccccc}
\hline \multirow{2}{*}{ Run } & \multicolumn{2}{c}{ Experimental Variable } & & \multirow{2}{*}{ Conv. \% } & 5-HMF Yield (\% Mole) \\
\cline { 2 - 4 } & $\boldsymbol{A}(\mathbf{m g} / \mathbf{m L})$ & $\boldsymbol{B}\left({ }^{\circ} \mathbf{C}\right)$ & $\boldsymbol{C}$ (min) & & 83.45 \\
\hline 1 & 5.00 & 140.00 & 180.00 & 85.61 & 75.81 \\
2 & 5.00 & 180.00 & 60.00 & 78.23 & 99.06 \\
3 & 7.50 & 160.00 & 120.00 & 99.63 & 26.17 \\
4 & 7.50 & 193.64 & 120.00 & 30.31 & 24.31 \\
5 & 10.00 & 140.00 & 60.00 & 26.87 & 35.69 \\
6 & 5.00 & 140.00 & 60.00 & 37.25 & 42.10 \\
7 & 10.00 & 180.00 & 180.00 & 93.92 & 50.12 \\
8 & 10.00 & 180.00 & 60.00 & 53.45 & 79.10 \\
9 & 7.50 & 160.00 & 180.00 & 88.32 & 82.45 \\
10 & 5.00 & 180.00 & 180.00 & 95.64 & 47.32 \\
11 & 10.00 & 140.00 & 180.00 & 83.59 & \\
12 & 7.50 & 140.00 & 120.00 & 50.71 & \\
\hline
\end{tabular}

\section{Conclusions}

The conversion of fructose into 5-HMF catalyzed by heteropolyacid salts was investigated. Among the catalysts tested, $\mathrm{CePW}_{12} \mathrm{O}_{40}$ showed the highest catalytic activity for the dehydration of fructose to 5-HMF. The optimal 5-HMF yield was $99.40 \%$ under the following reaction conditions: $5.48 \mathrm{mg} / \mathrm{mL}$ fructose loading; $158{ }^{\circ} \mathrm{C}$ temperature and 164 min reaction time. A kinetic analysis was also conducted, and the activation energy and pre-exponential factor for the $\mathrm{CePW}_{12} \mathrm{O}_{40}$-catalysed conversion of fructose into 5-HMF were obtained.

Acknowledgments: This project was sponsored by the National Natural Science Foundation of China under grant number 21476021.

Author Contributions: The experimental work was designed by Y.S. and C.H.; Y.S. and X.W. performed the experiments; Y.Q., Y.L. and B.C. analyzed the data; X.W. drafted the paper. The manuscript was amended using the comments of all authors. All authors have given approval for the final version of the manuscript.

Conflicts of Interest: The authors declare no conflict of interest. 


\section{References}

1. Corma, A.; Iborra, S.; Velty, A. Chemical routes for the transformation of biomass into chemicals. Chem. Rev. 2007, 107, 2411-2502. [PubMed]

2. Wang, X.; Song, Y.; Huang, C.; Liang, F.; Chen, B. Lactic acid production from glucose over polymer catalysts in aqueous alkaline solution under mild conditions. Green Chem. 2014, 16, 4234-4240.

3. Shi, W.; Li, S.; Jia, J.; Zhao, Y. Highly efficient conversion of cellulose to bio-oil in hot-compressed water with ultrasonic pretreatment. Ind. Eng. Chem. Res. 2013, 52, 586-593.

4. Binder, J.B.; Raines, R.T. Simple chemical transformation of lignocellulosic biomass into furans for fuels and chemicals. J. Am. Chem. Soc. 2009, 131, 1979-1985. [CrossRef] [PubMed]

5. Climent, M.J.; Corma, A.; Iborra, S. Converting carbohydrates to bulk chemicals and fine chemicals over heterogeneous catalysts. Green Chem. 2011, 13, 520-540. [CrossRef]

6. Su, Y.; Brown, H.M.; Huang, X.; Zhou, X.D.; Amonette, J.E.; Zhang, Z.C. Single-step conversion of cellulose to 5-hydroxymethylfurfural (HMF), a versatile platform chemical. Appl. Catal. A 2009, 361, 117-122. [CrossRef]

7. Lv, X.N.; Li, G.; Yang, F.; Gao, P.; Liu, Z.H.; Meng, L.; Yu, X.Q. Homogeneous degradation of cotton cellulose into furan derivatives in $\mathrm{ZnCl} 2$ solution by integration technology of reaction and extraction. Ind. Eng. Chem. Res. 2013, 52, 297-302.

8. Rosatella, A.A.; Simeonov, S.P.; Fradea, R.F.; Afonso, C.A. 5-Hydroxymethylfurfural (HMF) as a building block platform: Biological properties, synthesis and synthetic applications. Green Chem. 2011, 13, 754-793. [CrossRef]

9. Agirrezaba-Tellería, I.; Gandarias, I.; Arias, P.L. Heterogeneous acid-catalysts for the production of furan-derived compounds (furfural and hydroxymethylfurfural) from renewable carbohydrates: A review. Catal. Today 2014, 234, 43-58.

10. Tong, X.L.; Ma, Y.; Li, Y.D. Biomass into chemicals: Conversion of sugars to furan derivatives by catalytic processes. Appl. Catal. A 2010, 385, 1-13. [CrossRef]

11. Zakrzewska, M.E.; Bogel-Łukasik, E.; Bogel-Łukasik, R. Ionic liquid-mediated formation of 5-hydroxymethylfurfural: A promising biomass-derived building block. Chem. Rev. 2011, 111, 397-417. [CrossRef] [PubMed]

12. Zhao, H.; Holladay, J.E.; Brown, H.; Zhang, Z. Metal chlorides in ionic liquid solvents convert sugars to 5-hydroxymethylfurfural. Science 2007, 316, 1597-1600. [CrossRef] [PubMed]

13. Román-Leshkov, Y.; Chheda, J.N.; Dumesic, J.A. Phase modifiers promote efficient production of hydroxymethylfurfural from fructose. Science 2006, 312, 1933-1937. [CrossRef] [PubMed]

14. Wang, T.; Nolte, M.W.; Shanks, B.H. Catalytic dehydration of C6 carbohydrates for the production of hydroxymethylfurfural (HMF) as a versatile platform chemical. Green Chem. 2014, 16, 548-572. [CrossRef]

15. Qi, X.; Guo, H.; Li, L. Efficient conversion of fructose to 5-hydroxymethylfurfural catalyzed by sulfated zirconia in ionic liquids. Ind. Eng. Chem. Res. 2011, 50, 7985-7989. [CrossRef]

16. Moreau, C.; Finiels, A.; Vanoye, L. Dehydration of fructose and sucrose into 5-hydroxymethylfurfural in the presence of 1-H-3-methyl imidazolium chloride acting both as solvent and catalyst. J. Mol. Catal. A 2006, 253, 165-169. [CrossRef]

17. Hu, S.; Zhang, Z.; Song, J.; Zhou, Y.; Han, B. Efficient conversion of glucose into 5-hydroxymethylfurfural catalyzed by a common Lewis acid $\mathrm{SnCl}_{4}$ in an ionic liquid. Green Chem. 2009, 11, 1746-1749. [CrossRef]

18. Hu, L.; Sun, Y.; Lin, L. Efficient conversion of glucose into 5-hydroxymethylfurfural by chromium (III) chloride in inexpensive ionic liquid. Ind. Eng. Chem. Res. 2012, 51, 1099-1104. [CrossRef]

19. Wei, Z.; Li, Y.; Thushara, D.; Liu, Y.; Ren, Q. Novel dehydration of carbohydrates to 5-hydroxymethylfurfural catalyzed by Ir and Au chlorides in ionic liquids. J. Taiwan Inst. Chem. E 2011, 42, 363-370. [CrossRef]

20. Carlini, C.; Patrono, P.; Galletti, A.M.R.; Sbrana, G. Heterogeneous catalysts based on vanadyl phosphate for fructose dehydration to 5-hydroxymethyl-2-furaldehyde. Appl. Catal. A 2004, 275, 111-118. [CrossRef]

21. Moreau, C.; Durand, R.; Razigade, S.; Duhamet, J.; Faugeras, P.; Rivalier, P. Dehydration of fructose to 5-hydroxymethylfurfural over H-mordenites. Appl. Catal. A 1996, 145, 211-224. [CrossRef]

22. Armaroli, T.; Busca, G.; Carlini, C.; Giuttari, M.; Galletti, A.M.R.; Sbrana, G. Acid sites characterization of niobium phosphate catalysts and their activity in fructose dehydration to 5-hydroxymethyl-2-furaldehyd. J. Mol. Catal. A 2000, 151, 233-243. [CrossRef] 
23. Qi, X.; Watanabe, M.; Aida, T.M.; Smith, R.L., Jr. Catalytical conversion of fructose and glucose into 5-hydroxymethylfurfural in hot compressed water by microwave heating. Catal. Commun. 2008, 9, 2244-2249. [CrossRef]

24. Shimizu, K.; Uozumi, R.; Satsuma, A. Enhanced production of hydrox ymethylfurfural from fructose with solid acid catalysts by simple water removal methods. Catal. Commun. 2009, 10, 1849-1853. [CrossRef]

25. Qu, J.P.; Zhou, Y.H.; Liu, X.Y.; Qiu, J.J.; Qu, L.H. A method to produce 5-hydroxymethylfurfural. Chinese Patent 10, CN 101289435, 22 October 2008.

26. Zhao, Q.; Wang, L.; Zhao, S.; Wang, X.; Wang, S. High selective production of 5-hydroymethylfurfural from fructose by a solid heteropolyacid catalyst. Fuel 2011, 90, 2289-2293. [CrossRef]

27. Qi, X.H.; Watanabe, M.; Aida, T.M.; Smith, R.L. Selective conversion of D-fructose to 5-hydroxymethylfurfural by ion-exchange resin in acetone/dimethyl sulfoxide solvent mixtures. Ind. Eng. Chem. Res. 2008, 47, 9234-9239. [CrossRef]

28. Qi, X.; Watanabe, M.; Aida, T.M.; Smith, R.L. Fast Transformation of Glucose and Di-/Polysaccharides into 5-Hydroxymethylfurfural by Microwave Heating in an Ionic Liquid/Catalyst System. ChemSusChem 2010, 3 , 1071-1077. [CrossRef] [PubMed]

29. Bicker, M.; Hirth, J.; Vogel, H. Dehydration of fructose to 5-hydroxymethylfurfural in sub-and supercritical acetone. Green Chem. 2003, 5, 280-284. [CrossRef]

30. Qu, Y.S.; Huang, C.P.; Song, Y.L.; Zhang, J.; Chen, B.H. Efficient dehydration of glucose to 5-hydroxymethylfurfural catalyzed by the ionic liquid, 1-hydroxyethyl-3-methylimidazolium tetrafluoroborate. Bioresour. Technol. 2012, 121, 462-466. [CrossRef] [PubMed]

31. Gan, J.; Yuan, W.Q. Operating condition optimization of corncob hydrothermal conversion for bio-oil production. Appl. Energy 2013, 103, 350-357. [CrossRef]

32. Means, N.E.; Starbuck, C.J.; Kremer, R.J.; Jett, L.W. Effects of a food waste-based soil conditioner on soil properties and plant growth. Compost Sci. Util. 2005, 13, 116-121. [CrossRef]

33. Utami, S.P.; Amin, N.A.S. Optimization of glucose conversion to 5-hydroxymethylfulfural using [BMIM] Cl with ytterbium triflate. Ind. Crops Prod. 2013, 41, 64-70. [CrossRef]

34. Liu, J.; Yan, M.; Zhang, Y.K.; Du, K.F. Study of glutamate-modified cellulose beads for Cr (III) adsorption by response surface methodology. Ind. Eng. Chem. Res. 2011, 50, 10784-10791. [CrossRef]

(C) 2016 by the authors; licensee MDPI, Basel, Switzerland. This article is an open access article distributed under the terms and conditions of the Creative Commons by Attribution (CC-BY) license (http:/ / creativecommons.org/licenses/by/4.0/). 